\title{
Homeownership in Old Age at the \\ Crossroad Between Personal \\ and National Histories
}

Viola Angelini, Anne Laferrère, Guglielmo Weber 


\section{Homeownership in Old Age at the Crossroad Between Personal and National Histories}

Viola Angelini, Anne Laferrère and Guglielmo Weber

\subsection{Homeownership as old age insurance}

Compared to other forms of savings for old age, homeownership offers some advantages. Purchasing a home is similar to purchasing an annuity that would insure housing consumption. Moreover, the home may be seen as a secure asset in case of need and perceived as a substitute for the purchase of long term care insurance. It is also a family asset that may be transmitted to the next generation. These advantages are weighted against the drawbacks of over consumption in old age (for those who are house rich and cash poor), low portfolio diversification (the price risk may be important if all assets are in the home), and illiquidity (drawing equity in case of need is not easy).

A majority of the European elderly are homeowners. Homeownership rate is above 70 percent for those aged 50-79. The life cycle model of saving under borrowing constraints predicts a hump shaped homeownership age profile (Artle and Varayia, 1978). The ownership rate increases with age as people save and become home-owners, and declines in old age as people draw on their housing equity. The model is actually complicated by large mobility costs and housing illiquidity. This delays homeownership to a time when mobility is expected to be lower, and reduces equity withdrawal. Hence the decline in old age of home ownership is open to debate.

Homeownership age profiles and rates vary within a country among groups of population (by income, say); across countries and over time for different cohorts. This variation might stem from differences in national housing policies, such as credit constraints and mortgage market laws, rental regulations and social housing availability. It might also stem from personal housing history, such as parents' homeownership, inheritance, or migration. Personal histories are themselves shaped by more general history and country policies, just as housing policy is in turn influenced by the local political and economic context. 


\subsection{A digest of housing policies in Europe}

Housing has been a target for government intervention in most countries, both in terms of welfare (because a home is a necessity; because of housing consumption externalities), and in terms of credit market development (housing is an expensive investment). Besides, the last century saw two world wars that heavily destroyed homes or halted construction, the Great Depression before WWII, and, after WWII, a baby boom that mechanically increased home space demand, then overall home demand after 1965 when the first baby boomers began setting up their own households. Housing shortage was a familiar feature of the 1950s until the end of the 1970s. Those characteristics make housing policy both a social policy and an economic policy. Housing conditions were seen as linked to health and welfare, hence part of a desirable 'social' policy, but in most countries the housing stock remained private property and the market played some role. Besides, new construction fuelled growth, hence the broader economic policy aspect. The aims of government intervention were always somewhat mixed, and the form it took has varied in space and time.

Indeed, many forms of public intervention (at various levels, local or national) have existed over the last century. Nominal rents were blocked during or after WWI in Belgium, Switzerland, Sweden, France, Germany, Italy, Austria, Spain (1939), after WWII in Denmark and Greece. Construction was subsidized through various forms of 'social' rented dwellings, mostly after WWII (Sweden, Denmark, Germany, France, Austria and, then, the Netherlands and Italy). After 1970, direct allowances for rents began to be granted to low-income tenants, a departure from the indirect subsidy of social housing that was more universal as in most countries exceeding the income eligibility requirement was not a reason for leaving social housing or paying higher rent (France, Germany) and in some places entry into subsidized housing was not even means-tested (Sweden, Denmark and the Netherlands). Even after the hard first-generation rent controls were dropped, a variety of second generation rent regulations and sitting tenants protection are still prevalent in most if not all continental European countries.

After the period of direct subsidy to social housing, but sometimes in parallel, home ownership was encouraged. The classical arguments in favor of homeownership are the following. Homeownership reduces eviction risk, rent risk and avoids the "fundamental rental externality" of Henderson and Ioannides (1983). Eviction risk has been close to zero for most SHARE cohorts, as tenants were well protected. Rent risk is quite low for most sitting tenants, even if it may become important in the near future. The fundamental rental externality whereby tenants take little care of their home, inducing a moral hazard premium in market rents, may explain why so many consumers prefer owning to renting and why it might be in the public interest to promote it. Since WWII, homeownership has been encouraged by subsidized interest rates; by tax incentives such as deduction of mortgage interest from taxable income (Sweden, Denmark, the Netherlands and 
France); no taxation of imputed rent (except in Belgium, Sweden, Denmark, the Netherlands, Spain, Italy and Greece); no taxation of capital gains on homes; or even, lately, the sale of social housing to tenants (the Netherlands, Sweden, Italy and the former Eastern Block countries). For low-income, low-tax people the advantages of tax breaks are limited. Also, tax incentives may be fully capitalized in house prices, making first time buying more difficult. For this reason, there was a move towards deregulation of mortgage markets in all countries: after the 1970s in Germany, at the end of the 1980s in Austria, France, Spain, Sweden, in the 1990s in Greece, Italy, Poland and the Czech Republic. It has been shown that the development of the mortgage market helped young people's access to homeownership (e.g. via increased loan to value ratios).

We use SHARELIFE data also to document the two main movements that drove the housing life cycle of Europeans: the move to urban areas and renting, then the move towards more suburban areas and ownership. While 43 percent of the childhood homes of those born before 1935 were in a village or a rural area, it is the case for only 36 percent of the baby boomers. The drive led to a huge increase in comfort. When those born before 1935 were aged 10, 46 percent had no running water, nor toilet, nor central heating in their home; only 21 percent of the baby-boomers lived in similar conditions in their childhood. However, most subsidized rental housing was built in the 1960s with more emphasis on quantity than quality, and most if not all were flats. The reason for the wide spread move toward homeownership may then also be found in the desire for 'different' homes (typically not available for rent because of the externality described above): more space, houses and better neighbourhoods, as opposed to flats in city centers or suburbs. Moreover, there might have been a filtering up process through social housing as a step towards home ownership. The intuition is that in countries with a well-developed social housing sector (Denmark, Sweden and France) access to ownership was also easier ceteris paribus: it left time to build up a down payment, to settle in a job and a family, and helped young people move out (see Angelini, Laferrère and Pasini, chapter 6 of this volume).

\subsection{Homeownership rate by age, cohort and country}

SHARELIFE offers the unique opportunity to envision a century of access to homeownership in Europe. It allows getting at "true" age profiles free from cohort effects, at least for those who survived to the day of the interview. The welldocumented differential mortality by wealth implies that we may overestimate the proportion of homeowners in the overall population. The presence of time effects may also blur the picture.

We define three broad cohorts: cohort 1 of those born before 1935 (24 percent of the sample), cohort 2 of those born between 1935 and 1944 (31 percent) and cohort 3 of those born between 1945 and up to 1954 (45 percent), whom we call 
the "baby-boomers". Even more important than date of birth is the date around which each cohort started to set up their own household: before the end of WW2 for cohort 1, after WW2 for cohort 2 and at the end of the 1970s for cohort 3.

In Table 7.1 we show the proportion of individuals who are or have ever been home-owners (after they left their parents' home), by cohort and country. This is an underestimate of the proportion of individuals who experience home-ownership at any point in their lives, as some individuals may become home-owners during their remaining life span. This underestimation may be of some consequence for cohort 3 - at least in some countries, where mortgage markets function less well and owning through inheritance is more common.

There are marked differences between cohorts: barely 65 percent of our eldest cohort ever owned their home, the rate jumps to 68 percent for the middle cohort and for the baby boomers. The difference between cohort 1 and cohort 2 is spectacular in the Nordic countries, in the Netherlands, Germany, Switzerland or France where it is between 6 and 11 percentage points and corresponds to the development of the credit market for homes and reconstruction after WWII. Those born after 1934 (cohort 2) started benefiting from it at the time they formed a household, after 1944. There are some exceptions: in Greece the rate is stable at a high 86 percent.

Table 7.1: $\quad$ Percentage of individuals who ever owned a home, by cohort and country

\begin{tabular}{lrrrrrrrrrrrrrr}
\hline Cohort & SE & DK & DE & NL & BE & FR & CH & AT & ES & IT & GR & PL & CZ & All \\
\hline 3. $>1944$ & 84.9 & 93.2 & 55.0 & 80.5 & 90.3 & 77.6 & 62.0 & 61.5 & 74.5 & 67.4 & 87.3 & 57.2 & 61.5 & 68.4 \\
2. $1935-44$ & 87.2 & 90.0 & 54.8 & 67.8 & 86.7 & 79.7 & 62.2 & 65.1 & 77.0 & 72.9 & 85.4 & 54.7 & 56.6 & 67.9 \\
1. $<1935$ & 80.7 & 83.1 & 48.5 & 57.0 & 83.5 & 72.7 & 52.9 & 61.2 & 74.6 & 69.4 & 86.3 & 51.9 & 51.2 & 64.7 \\
Total & 84.5 & 90.0 & 53.4 & 71.9 & 87.5 & 76.7 & 59.7 & 62.6 & 75.2 & 69.6 & 86.5 & 55.5 & 58.1 & 67.3 \\
\hline
\end{tabular}

The evolution for the baby-boomers (cohort 3) is less spectacular, and in some countries (Sweden, France, Spain, Italy, Austria) they were even less likely than the preceding cohort to ever own a home.

Figure 7.1 presents the complete age profile of homeownership for the three cohorts, by country. We define ownership as 1 if the person (or her spouse) owned during the entire 10-year age period, 0 if she never owned, and $y / 10$ if she owned for y years during the 10-year period. One caveat has to be mentioned: the samples get small for countries with low homeownership rates (Austria, Germany, Poland and Czech Republic).

Figure 7.1: $\quad$ Age-cohort homeownership profiles 


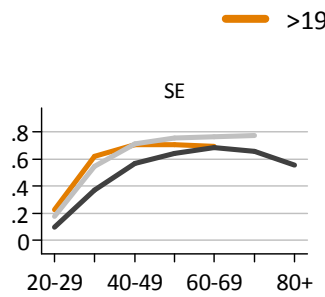

$1944-1935-44 \longrightarrow 1935$

DE

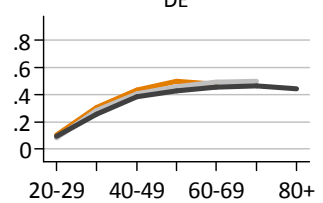

FR

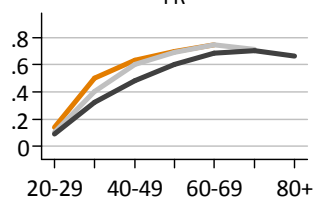

ES
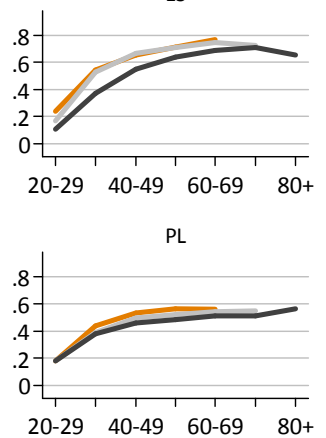

DK

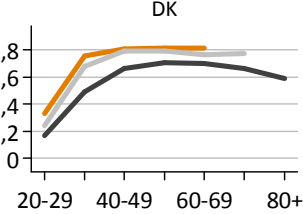

$\mathrm{NL}$

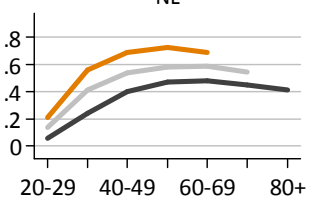

$\mathrm{CH}$

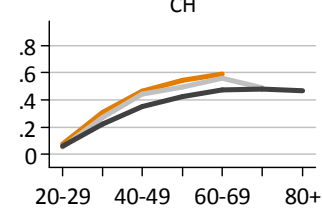

IT

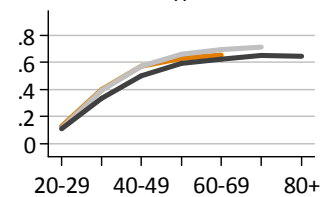

$\mathrm{CZ}$

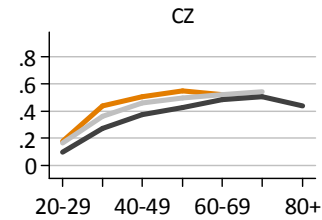

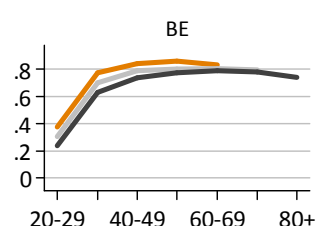

AT

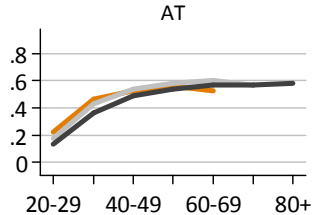

GR

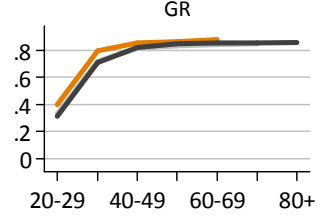

We are now able to qualify the cohort effects in more detail. The curves show (cohort-specific) age profiles. The vertical distance between curves measures a first type of cohort effect: the difference between cohorts in homeownership rates at each age. Another type of cohort effect is the variation from one cohort to the next in the slopes of the curves, which measure the steepness of the age profiles.

\section{Age Profiles}

The age profiles look the same nearly everywhere: an increase in homeownership up to age 50-59, then a leveling up and a small moving out of ownership in old 
age, after 70 in Denmark, Sweden and the Netherlands, and rather after age 80 in the other countries (except Poland and Greece where no moving out of homeownership is apparent).

This pattern confirms the life-cycle theory that predicts equity withdrawal in old age as a way to maintain a stable standard of living. To the extent that financial instruments to release home equity are not available, selling and moving into rented accommodation may be an efficient way to free resources. The alternative is to draw equity by buying cheaper homes, as documented in Angelini, Brugiavini and Weber, in chapter 8 of this volume.

\section{Cohort effects of the first type: the spread of home ownership}

Let us look at the first type of cohort effect, measured by the vertical distance between the curves. If one curve is above another, it means the corresponding cohort has higher ownership rates than the other at all ages. At first glance, such cohort effect is large between cohort 1 and cohort 2, in Sweden, Denmark, France, Spain, the Netherlands, (West) Germany (not shown separately on Figure 7.1) and the Czech Republic; it is smaller in Belgium, Austria, Switzerland, Poland and Italy. This effect could be due to public policies encouraging home ownership in the 1960s and 1970s. Besides home prices were low and real interest rates were very low because of inflation. By contrast, in most countries, the progression towards homeownership stopped for cohort 3, with the exception of the Netherlands and East Germany (not shown separately in Figure 7.1). While some will still enter homeownership later in life, the slower progress toward homeownership might come as a surprise as it coincides with the progressive liberalization of credit. It could be that mortgage development was eaten up by increases in home prices, which hit first time homebuyers, together with the economic crisis of 1973-1979.

\section{Second type of cohort effects: earlier access to home ownership thanks to credit}

Even if the profiles look alike, they are shaped by different histories. Such cohort effects of the second type can appear by a look at the steepness of the age profile.

For all cohorts, homeownership is infrequent below 30, except in Greece where more than 25 percent own. In Greece a third of these young home owners report they received it as a gift or bequest. The proportion of heirs of this young age group is also high in Spain, Italy, Austria, Poland and Czech Republic, but the ownership rate is lower (less than 20 percent). The slope between the first two age groups (20-29 and 30-39) is steepest in Greece and Belgium. In those two countries the profile is rather flat above 40 . However, the story differs: as we said, inheritance is prevalent in Greece, where help from family is also frequently mentioned ( 21 percent); only 6 percent mention a gift or inheritance in Belgium, where 76 percent of the 20-29 and 75 percent of the 29-39 got a mortgage. The interesting point is that the slope gets steeper and steeper from one cohort to the next in many countries. We interpret it as following the development of mortgage and 
credit markets which made it easier to borrow against future income or to access mortgages at a younger age in those countries.

Indeed, Figure 7.2 shows that from one cohort to the next not only access to home ownership increased, but it happened earlier. Median first home ownership age was 31 for the owners of cohort 1, 29 for cohort 2, and 27 for cohort 3 . Among those who occupied a home as owners, 31 percent (58) purchased or got one before age 30 (age 40) for the older cohort, 36 percent (67) for the middle cohort, and 46 percent (75) for the baby boomers.

Figure 7.2: Distribution of the age of first home-ownership, by country and cohort

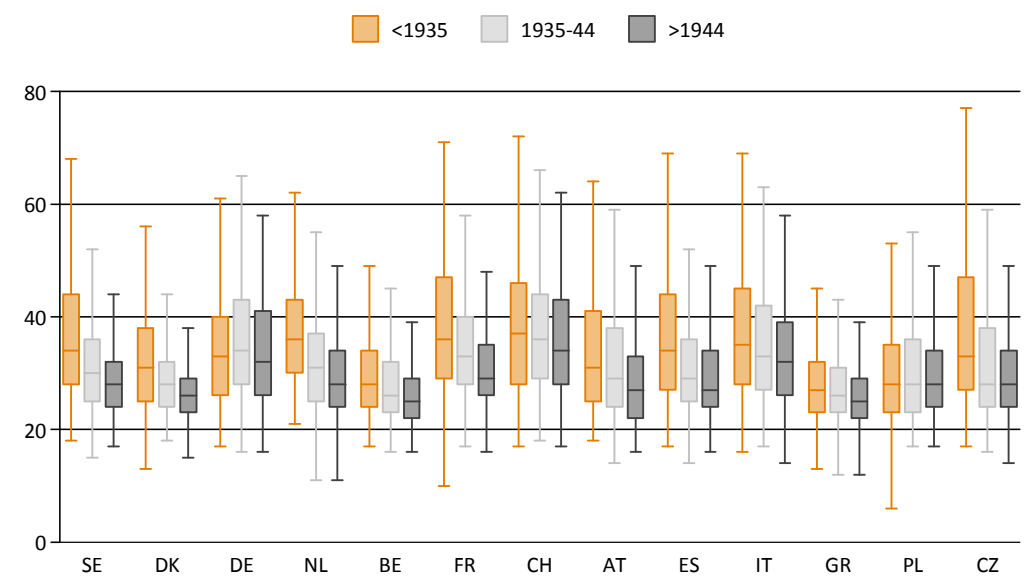

These findings point to very large differences between cohorts in homeownership profile. In the Netherlands 48 percent of the oldest cohort owned when aged 6069, while for the baby-boomers currently aged 60-69 the home ownership rate is 72 percent. In France the rate went from 67 to 76 percent and in Denmark from 72 to 82 . Even if the increase was smaller in some other countries home ownership rates of the future elderly are high. The question of using this housing equity optimally to finance old age has to be raised.

\subsection{Tenure and location over the life-cycle}

A home is a place to live, and owning and renting differ in that respect, as most owned homes are houses in low density areas, when rentals are flats in high density areas. Over the life cycle the most likely move is from the parental house in a rural area to a flat in the city, to a house in the suburbs or a more rural area, and 
finally sometimes to a flat in a city again. This can clearly be observed for our cohort 1: 33 percent of their parental homes were owned and in rural areas or small town, 31 percent of the independent homes where they moved before age 30 were rented in cities or suburbs, 42 (56) percent of homes where they moved in between age 30 and 39 (between age 40 and 59) were owned, then 50 percent of homes where they moved in between age 60 and 69, down to 16 percent after 80 as rent free becomes the main tenure mode in case of a move.

Figure 7.3 presents the age profiles of the rate at which individuals live in a rural area, a village or a small town, for our three cohorts, for four example countries. This includes home-owners, renters, but also those living rent-free (in the parental home when young, in their children's home when old) or even in nursing homes.

Figure 7.3: Age-cohort profiles of living in a rural area or small town

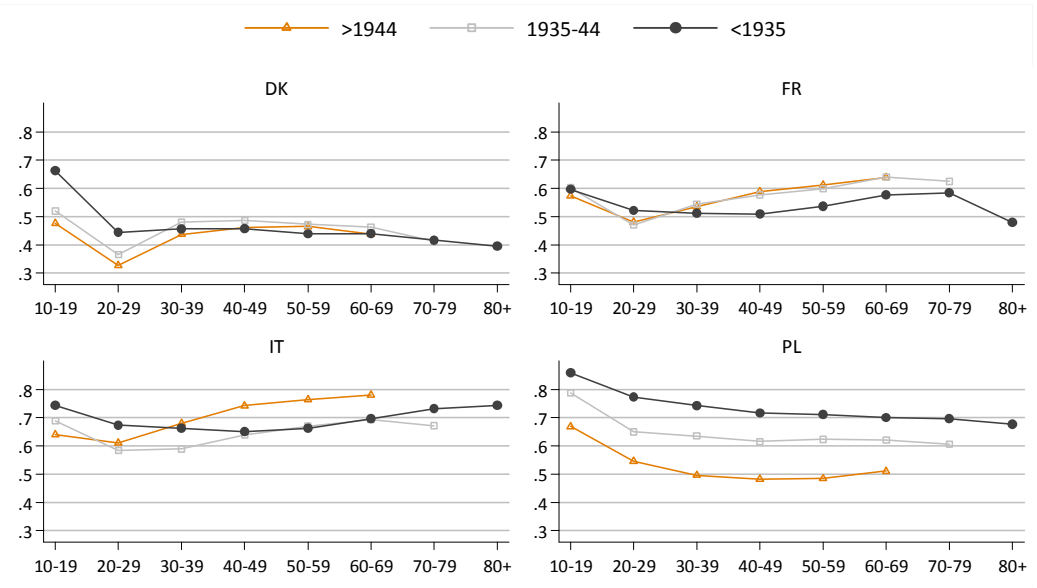

In all countries and for all cohorts there is a dip on entry into adulthood when people move to the city. This is normally followed by a period when the age profiles are flat, then slowly rising as some city flat dwellers move to low density areas as they enter into homeownership and houses. At the very end of life the profiles are flat again, or even declining as the oldest old prefer to be closer to the services provided by cities. The cohort effects vary strikingly by country. In countries such as Poland at the bottom right of Figure 7.3 (Greece, Spain, and the Czech Republic would be the same), each cohort is less likely to live in a village or small town setting than the preceding one, following the decline in agriculture that took place earlier in the other countries. No return to the cities is seen there, as indeed the homeownership profiles are also rather flat, except for the Spanish younger cohort who has entered into the process. In countries such as Belgium, France, Germany or Austria the adult younger cohort is more likely to live in a low density area than 
the oldest cohort, as the development of homeownership went with a clear move towards houses and gardens. This seems also to have happened more recently in Italy. In old age the location choices of some baby-boomers might become an issue if services are located in more densely located areas.

\subsection{How mortgages help to become homeowners}

Figure 7.4 presents the proportion of owners who accessed homeownership via a credit or a mortgage when they were aged below 40 , by cohort and country. The increase between cohort 1 and cohort 2 is more than 20 percentage points in France (from 58 to 79 percent, catching up with the two Nordic countries, the Netherlands, Switzerland and Belgium where mortgages where already developed before WWII) and Germany (from 42 to 65 percent), even if this country somewhat lags behind. The increase, from an already high level, has been important in the Netherlands where most if not all of the younger cohort homeowners got a mortgage. For some other countries, housing credit did not benefit a majority of those cohorts, even if the progression over the century has been important: Spain, Italy and the Czech Republic.

As the mortgage industry developed, other means of access to homeownership declined (Figure 7.5). For our older cohort in "central Europe" countries (Czech Republic, Poland, Austria, Germany), Italy and Greece more than a quarter of those who accessed homeownership before age 40 did it through a family inheritance or a gift. The proportion was only between 10 and 20 percent in Spain, Switzerland, France and Belgium, and much lower elsewhere. For the babyboomers the proportion is lower, but it remains strikingly high (around 25 percent) in Poland, Czech Republic, Greece, Austria and Italy. It is still 16 percent in Germany.

The decline in inheritance helped democratize access to homeownership. However, the family remains an important source of help for all cohorts. Even if people do not inherit a family home directly, the parents help them buying it (Figure 7.6). The help is mentioned by more than 10 percent of baby-boomers (who acquired a home before age 40) in Austria, Greece, the Czech Republic, Switzerland, Germany, Italy and Poland. We find again the opposition between Central-EastSouth-Europe and North-West.

Figure 7.4: Access to credit for purchase of a home before age 40, by country and cohort 


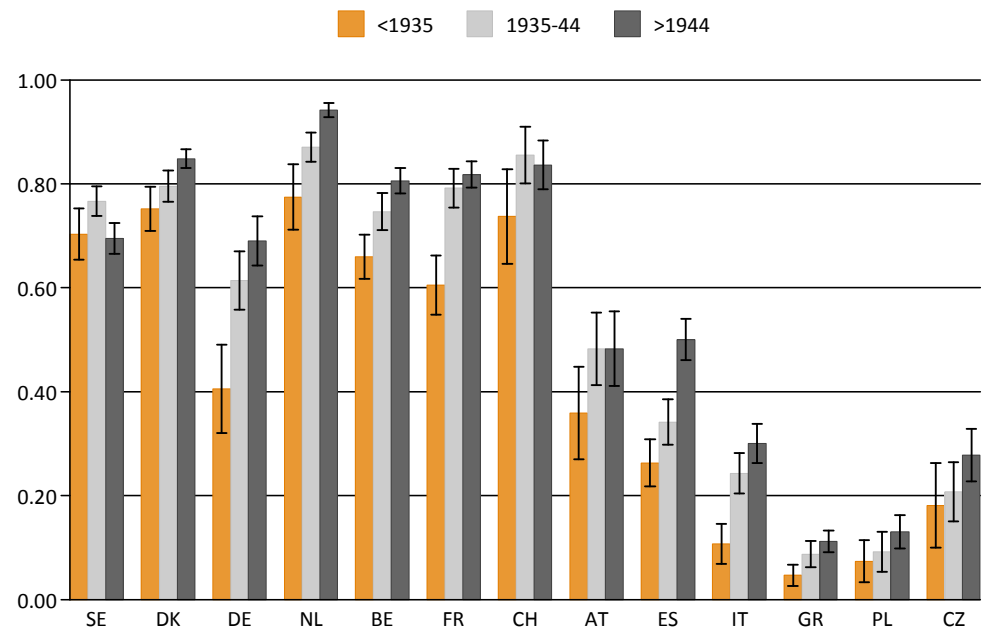

Figure 7.5: Inheritance and gift as a means of access to homeownership before age 40, by country and cohort

$\square<1935 \square 1935-44 \quad \square>1944$

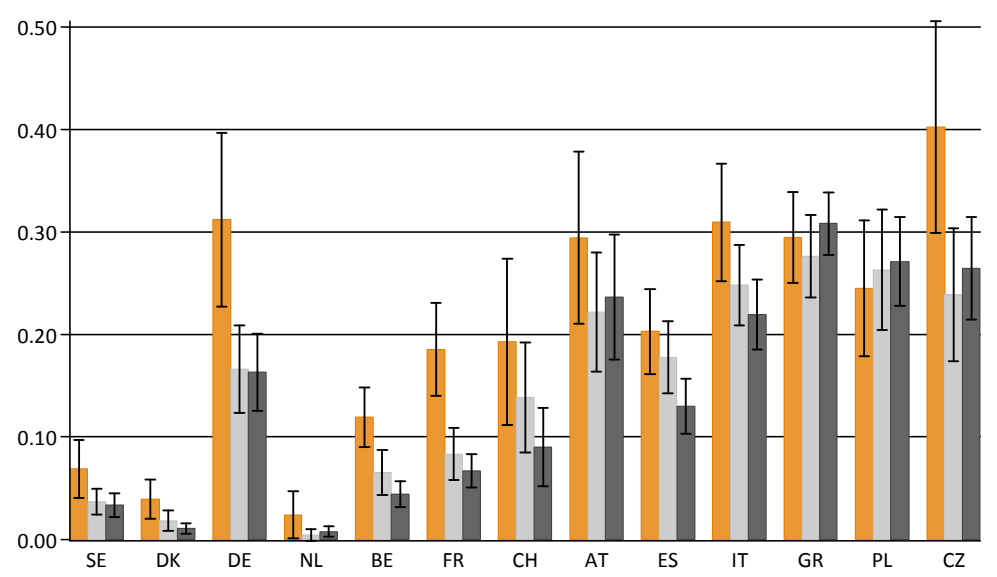

Figure 7.6: Purchase of a home before age 40 with help from family, by country and cohort 


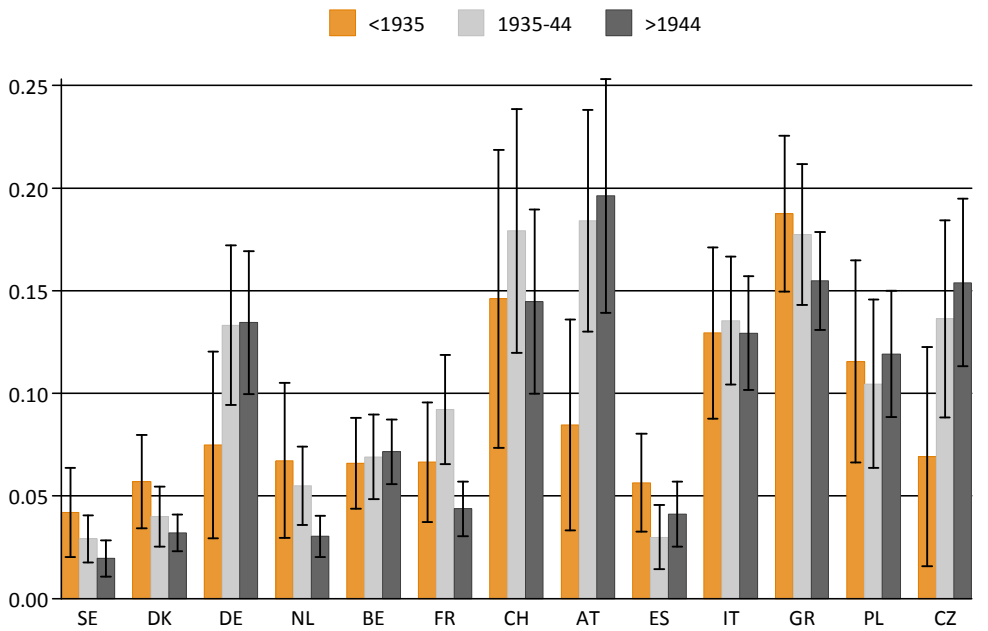

In Figures 7.7 and 7.8 we show that there is a striking correlation between the development of the mortgage market and how people access homeownership. In Figure 7.7 we plot the proportion of households who bought their house through a mortgage before age 40 against a very crude indicator of mortgage market development, that is the maximum loan-to-value ratio on mortgages (LTV) in the early 1980s. There is a clear positive relation: where the mortgage market is well developed, more people use it for their home purchases. At the same time, in countries where the mortgage industry is more developed, other means of access to homeownership, such as inheritances, gifts and family help, are less widespread (Figure 7.8).

These relations hold also over time. In countries where the maximum loan-tovalue ratio significantly increased between the early 1960s and the early 1980s, access to formal credit increased more than in countries where it did not change (the percentage difference between the two groups of countries is $8.1 \%$ ), while resorting to family help, gifts and inheritances became less common (-7.0\%).

Figure 7.7: Proportions who bought their home with a mortgage before 40 and maximum loan-to-value ratios 


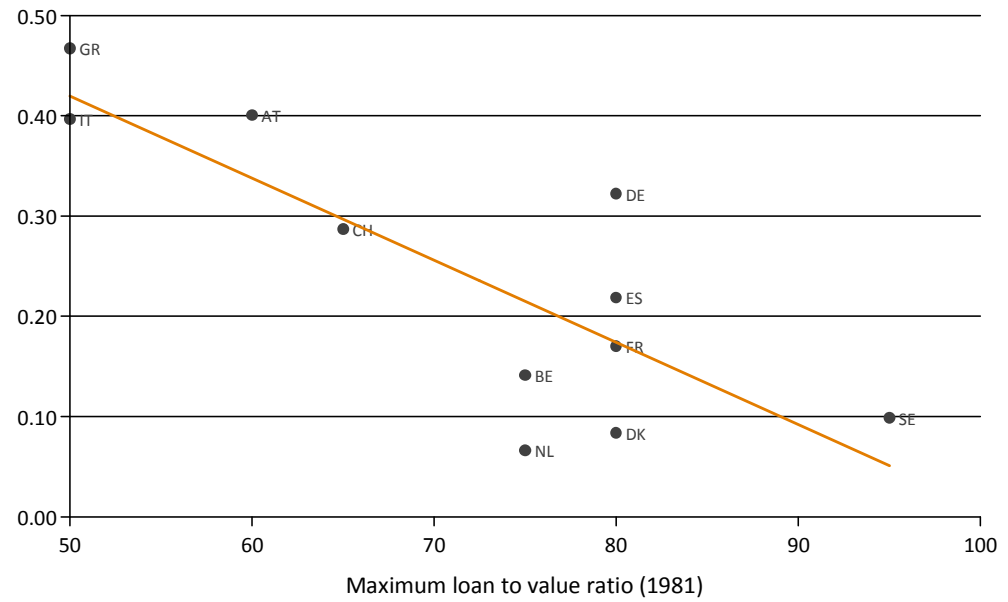

Figure 7.8: Proportions who received their home as a gift or acquired it with help from family before 40 and maximum loan-to-value ratios

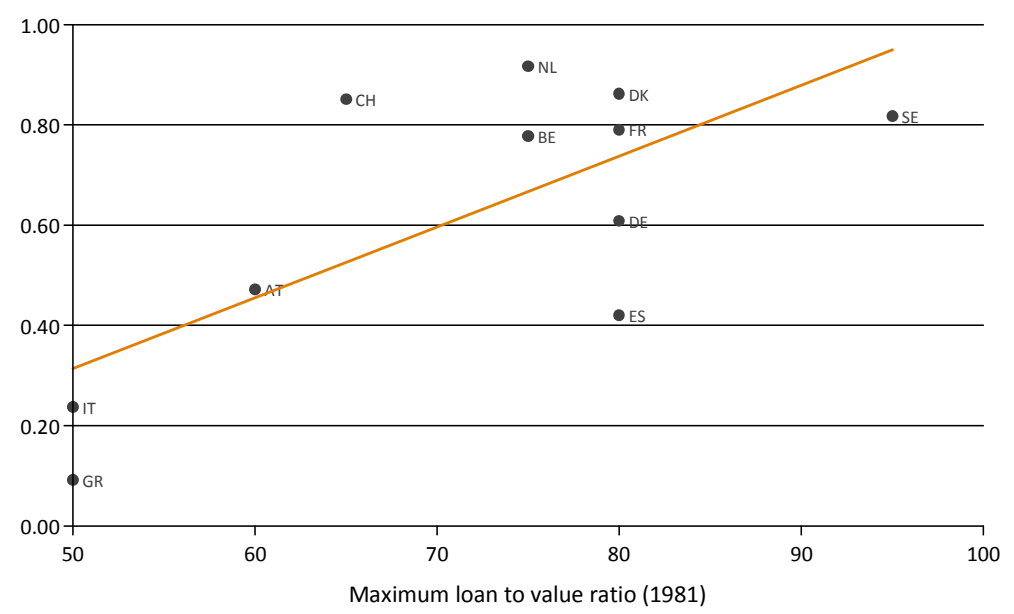

\subsection{Conclusions}

The secular changes in home-ownership rate and age patterns across European countries and cohorts are at the crossroad between the personal life histories of the 
SHARE respondents and broader national histories. They are related to housing policies, credit market development and socio-demographic characteristics of each country.

Our main conclusions are as follows:

- The overall lifecycle pattern is largely similar for all cohorts and countries: going from a parental home in a rural area, to being a tenant in a city, to owning (often in a less densely populated area). In some countries, renting is less common, and help from the parents is instrumental in acquiring a home.

- The differences in both location and slopes of home-ownership age profiles across cohorts are strong. Those born after 1935 had a much larger probability to ever be homeowner than those born before. For those born after 1945 , the overall probability is not larger but the access to homeownership took place much earlier in their lifecycle.

Our analysis may have implications for policy makers:

- The high homeownership rate of elderly Europeans, coupled with their relatively low levels of financial wealth in some countries, suggests that there is room for introducing new efficient home equity conversion products for those who might need to supplement a low pension.

- The location of some the new cohort of elderly in villages or small towns may call for a reorganization of old age care.

\section{References}

Artle, R., \& Varaiya, P. (1978). Life cycle consumption and ownership. Journal of Economic Theory, Vol. 18, pp. 35-58.

Henderson, J.V. \& Ioannides, Y.M. (1983). A model of housing tenure choice. American Economic Review, Vol. 73, pp. 98-111. 